\title{
Oversizing and HVAC system operation
}

\author{
Magdalena Stanescu ${ }^{1}$, Stanislaw Kaj1 ${ }^{1, *}$, and Louis Lamarche ${ }^{1}$ \\ ${ }^{1}$ École de technologie supérieure, Montreal, Canada
}

\begin{abstract}
This paper presents the monitoring results for the HVAC systems installed in a university building, which prove that oversizing is a real problem with existing systems. In our study, how the zones served by systems are grouped is a major cause of oversizing. This is particularly obvious when monitoring the systems serving the zones on a single facade; monitoring those in zones situated on two facades shows that additional reasons must also be considered as well. The monitoring presented in the paper is carried out on four systems, two serving zones on a single facade and two others serving zones located on two facades. Following the processing of the ensuing data, the results obtained show that the systems mostly function at between 55 and $65 \%$ of their design capacity. An analysis of these results indicates that a better design approach could reduce the total airflow rate of HVAC systems, reduce building energy consumption, and promote better systems operation.
\end{abstract}

\section{Introduction}

HVAC (heating, ventilation and air conditioning) systems are generally designed to ensure occupants' comfort. They are nevertheless known for their high energy consumption in commercial and institutional buildings. To improve energy efficiency, systems must be designed to operate at an optimal level; however, such optimisation may not provide the expected results without a simultaneous optimisation of their actual design as well. The design objectives in our context include, for example: (i) ensuring appropriate system capacity to meet building loads for design operation conditions, (ii) energy efficiency to reduce annual operating costs, and (iii) minimum life cycle costs. The first of these objectives always leads to system oversizing, with the next two going in the opposite direction. HVAC systems which are sized to meet design loads operate mostly at partial loads, with the fan airflow rate often being close to $50 \%$, which, in effect means close to the minimum recommended by ASHRAE [1]. In these conditions, the air supply temperature must be adjusted, and if zone loads are diversified, may result in over-cooling or overheating of some zones: this may in turn have an impact on occupants' comfort. Safety factors taken into consideration by designers mean that systems rarely attain $100 \%$ of installed capacity. Oversizing systems also increases the capital cost of HVAC units and of their air distribution systems.

\footnotetext{
* Corresponding author: Stanislaw.Kajl@etsmtl.ca
} 
Our goal in the present paper is to analyse HVAC system operation using the monitoring data for 2 summer months (cooling periods). To that end, we work to determine the degree of, and reasons for, oversizing of some HVAC systems in place in a university building in Montreal (Canada).

The article is broken down into the following three main parts:

1) Presentation and processing of HVAC system monitoring data;

2) Operation analysis of HVAC systems;

3) Introduction of an oversizing coefficient to quantify the oversizing of HVAC systems.

We end with an analysis of the results obtained, followed by conclusions.

\section{Brief description of building}

\subsection{Brief description of building}

The building studied is a former industrial building in Montreal, which was transformed into an academic institution in 1997. The building was further extended in 2007 and the total area is now $75,372 \mathrm{~m}^{2}$ (five floors). The building footprint is $14,800 \mathrm{~m}^{2}$, and it is almost squareshaped, with a large internal zone. The main zone house classrooms, laboratories, offices, corridors/storage spaces, a cafeteria, a kitchen and parking spaces.

\subsection{Overview of HVAC systems}

There are eighteen (18) HVAC systems installed in the building. Individual heat pumps connected to a closed-loop water system are used to cool spaces with specific requirements, such as server/telecom rooms. Figure 1 provides an overview of the building shape and system distribution on a typical floor ( $2^{\text {nd }}$ floor) following the building extension.

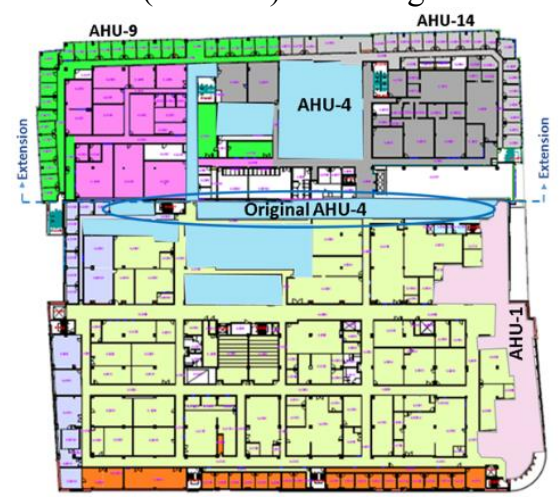

Fig. 1. System distribution on a typical floor.

Some systems only serve zones on a single facade (original systems before building extension), while the new systems installed during the building extension serve zones on two facades (two different orientations). In addition, an AHU-4 (Air Handling Unit) system presented below, and studied in 2002, served the south-west facade (external zones) and became a system serving only internal zones after the building extension. 


\section{Systems monitoring}

\subsection{Monitoring of AHU-4 system (2002)}

In [2], Kajl et al. show that several Variable Air Volume (VAV) systems of the studied building are largely oversized. They present the example of the AHU-4 system $(22,420 \mathrm{~L} / \mathrm{s})$ serving the south-west facade, which was monitored in 2002, in which case it was seen that the fan airflow rate (AFR_SUPPLY) never exceeded 60\% of the design airflow (Fig. 2). In addition, the supply air temperature set-point in the summer $\left(S P_{S U P P L Y}\right)$ rarely came in under $16^{\circ} \mathrm{C}$, and this mostly occurred during the system start-up. If this temperature were lower, the airflow rate could be reduced. Oversizing also affects the operation of chilled water and hot water valves [3], as well as that of outside and mixed air dampers.

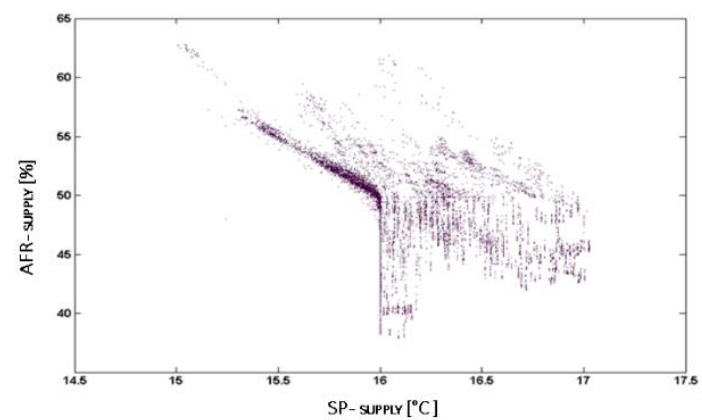

Fig. 2. Variation of AFR-supply and SP-supply (AHU-4, June 2002) (Kajl et al. [2]).

\subsection{AHU-1, AHU-9 and AHU-14 systems monitoring (2013)}

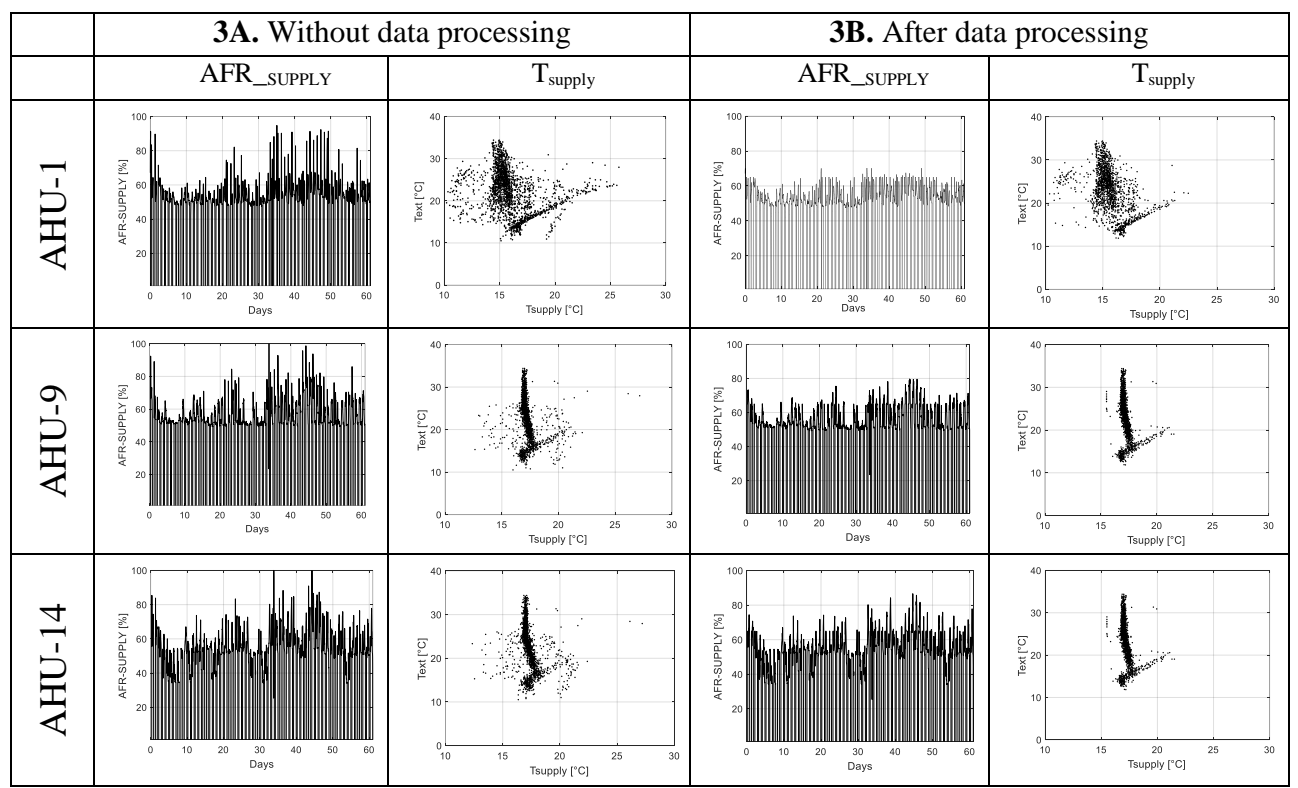

Fig. 3A, 3B. Variation of AFR-supply, $\mathrm{T}_{\text {supply }}$ and $\mathrm{T}_{\mathrm{ext}}$ (AHU-1, AHU-9 and AHU-14, Jun-July 2013). 
The AHU-1, AHU-9 and AHU-14 systems serving zones in perimeter sections of the building were monitored in June-July 2013. The AHU-4 system (studied in 2002) was not monitored during this period since it has become an internal system, as mentioned above. As an alternative, the AHU-1 system (20,533 L/s), comparable to AHU-4, was chosen because of its size and because it serves zones on a single facade (north-west orientation). The AHU-9 (20,518 L/s, south-west/south-east facades) and AHU-14 systems (18,242 L/s, southwest/north-west facades) serve perimeter sections located on two facades of the extended part of the building. In this case, the monitoring showed once again that the control system fan airflow rates are often less than $70 \%$ of the design airflow rate. Figure $3 \mathrm{~A}$ shows the results recorded for the AHU-1, AHU-9, and AHU-14 systems.

Looking at the results, it can firstly be seen that they confirm the oversizing of the systems. Secondly, peaks are observed during system start-up, while irregularities are seen while the systems are in operation. Examples of the system operation are presented below to explain how the data from the monitoring results were processed.

\subsection{Data processing}

Figure 4 shows the AHU-1 monitoring results recorded on 5 July 2013, including the irregularities mentioned above. The system experiences a significant start-up peak and abnormal operation in the evening and overnight. It is a hot day (maximum temperature of $32^{\circ} \mathrm{C}$ ), and the night before was hot as well (temperature of $23^{\circ} \mathrm{C}$ at $5 \mathrm{AM}$ ). The system starts at $4: 45$ in the morning, using $100 \%$ outside air before the chiller kicks in at 5:23. The supply temperature begins to drop at 5:30 and reaches its set-point (SP_SUPPLY) at 9 AM, about 4 hours after the system starts, but between 6:50 and 9 AM, it is lower than the SP_SuppLY. The rise of the fan airflow rate up to $90 \%$ is therefore due to the outside air temperature, which is relatively hot in the morning, and to the gap between the fan and chiller start up, which does not allow an adequate lowering of the supply air temperature. We believe that a non-oversized system can obviously perform a proper morning operation without increasing the airflow rate by up to $90 \%$, as actually occurred. A proper coordination of the fan and chiller start-up operations should avoid this problem. By anticipating this proper system start-up operation, we present, in Figure 3B, the results obtained by reducing the fan airflow rates during the morning operation by up to $65 \%$ of its design value because this airflow rate level is rarely reached outside the start-up operation. As mentioned above, Figure 4 also shows the system operating abnormally in the evening and overnight periods (with an increase of the air supply temperature) as a result of the unnecessarily prolonged fan operation during the night after the planned chiller stop. Figure 5 therefore shows the results with the corrections mentioned above applied to the fan air flow rates.

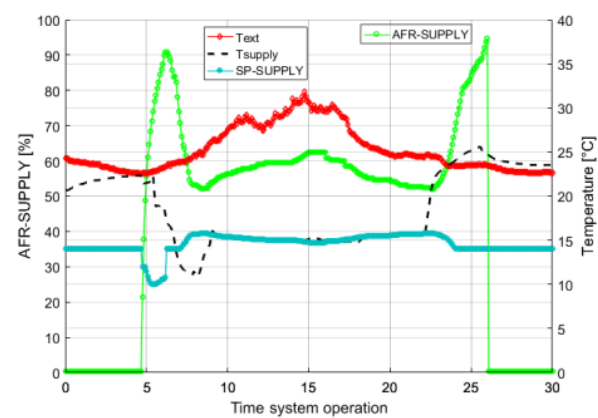

Fig. 4. Daily variation of AFR-suPPLy, SP-SUPPLY, $\mathrm{T}_{\text {supply }}$ and $\mathrm{T}_{\text {ext }}$, with start-up correction (AHU-1, 5/6 July 2013)

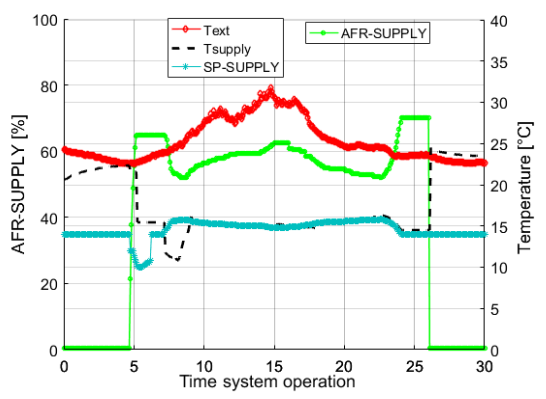

Fig. 5. Daily variation of AFR-suPPLY, SP-supply, $\mathrm{T}_{\text {supply }}$ and $\mathrm{T}_{\text {ext }}$, after data processing (AHU-1, 5/6 July 2013) 
As observed in Figure 3A, we found the same operating problems with the UTA-14 and UTA-1 systems.

An analysis of the recorded data shows that the peaks of the AHU-9 and AHU-14 systems during the building occupancy periods occur with the set-point $\left(S P \_S U P P L Y\right)$ equal to $15^{\circ} \mathrm{C}$ during the hottest summer days. For these set-points, the air supply temperature is mostly about $17^{\circ} \mathrm{C}$ (Figs. 3A, 3B and 6), which is $2^{\circ} \mathrm{C}$ higher than the set-point. Obviously, these air supply temperatures can be attributed to the oversizing of the systems, which now require relatively high $S P_{-} S U P P L Y$ set-points in order to avoid unstable operations of the fan.

The data processing, as mentioned before, consists in reducing the fan airflow rates during the start-up and abnormal operation of the systems. Figure $3 \mathrm{~B}$ shows the airflow rate variations $(A F R$-SUPPLY $)$ and the relationships between the outdoor temperature $\left(T_{\text {ext }}\right)$ and the air supply temperature $\left(T_{\text {supply }}\right)$ for the AHU-1, AHU-9, and AHU-14 systems after data processing.

Figure $3 \mathrm{~B}$ shows that the systems mostly operate at between $55 \%$ and $65 \%$ of their design capacity. The AHU-9 and AHU-14 systems exceed $80 \%$ of their design capacity only during a few days in July, which are the hottest days of the summer season. We also notice in Figure 3B that $T_{\text {supply }}$ can be further decreased, thus reducing the airflow rate of these systems and further amplifying the recorded effect of oversizing.

\section{Operating analysis of systems}

The monitoring results presented in this paper show that the four studied systems are oversized.

- The airflow rates for AHU-4 and AHU-1 rarely exceed $65 \%$ of design airflow, often with an air supply temperature above the lower limit. These are two systems serving zones on a single facade.

- The airflow rates for AHU-9 and AHU-14 sometimes reach $80 \%$ of their design capacity, but with the $T_{\text {supply }}$ above the set-point, as presented in the next section.

\subsection{AHU-9 control sequences analysis}

In order to evaluate the degree of oversizing in effect, an analysis of some control sequences is necessary. The set-point of the supply air temperature changes as a function of the outside temperature (for $T_{\text {ext }}=-20^{\circ} \mathrm{C}, S P_{S}$ SUPPLY $=19^{\circ} \mathrm{C}$ and for $T_{\text {ext }}=25^{\circ} \mathrm{C}, S P_{S} S U P P L Y=13^{\circ} \mathrm{C}$ ), followed by an adjustment according to the fan airflow rate (if the airflow rate $>90 \%$, the $S P_{\triangle}$ SUPPLY is decreased by $2{ }^{\circ} \mathrm{C}$, and if the airflow rate $<50 \%$, the $S P_{-} S U P P L Y$ is increased by $2{ }^{\circ} \mathrm{C}$ ). The linear variation is applied between the parameters presented above. The set-point

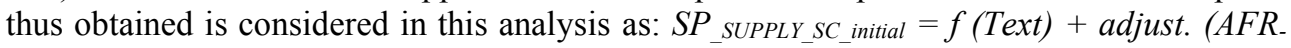
SUPPLY). However, when analysing the building automation software, we found that, in order to respect a fan airflow rate greater than $40 \%$ of the design value, while also respecting thermal comfort requirements, the SP_SUPPLY was artificially increased by $2{ }^{\circ} \mathrm{C}$ relative to the set-point indicated in the $S P_{-} S U P P L Y S C_{-}$initial control sequence. In the previous chapter, we explained the reasons for applied data processing, which consists in correcting the system airflow rate during system start-up and for abnormal system operations. For this analysis, and to avoid analysing combined monitoring and corrected data, we removed these system startup and abnormal systems operation from consideration. Figure 6 shows a comparison of the

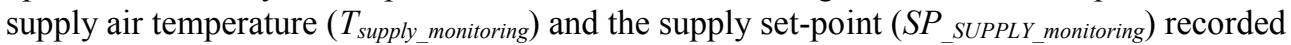
by monitoring, as well as the set-point of the supply air temperature calculated by applying the initial control sequence $S P_{-S U P P L Y} S C_{-}$initial. 


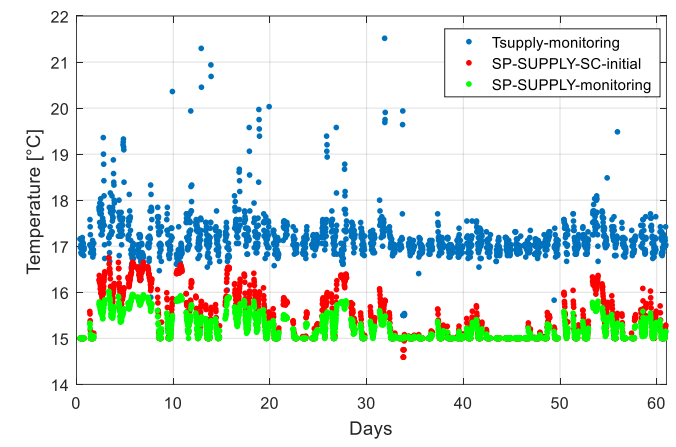

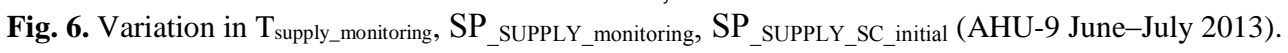

The principal conclusion that can be drawn here is that the supply air temperature $T_{\text {supply_monitoring }}$ is much higher than the $S P_{-}$SUPPLY_monitoring temperature, which thus ensures that the system airflow rate is greater than $40 \%$ (Figs. 3A, 3B and 7). It is also found that

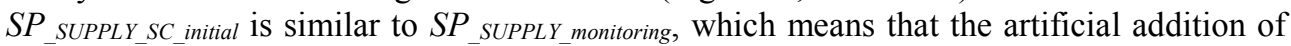
$2^{\circ} \overline{\mathrm{C}}$, mentioned above, during this period of the year gives a value of $S P P_{-} S U P P L Y$ similar to the one obtained according for the $S P_{-} S_{S P P L Y} S_{-}$initial. Given that $T_{\text {supply_monitoring }}$ values are much higher than the set-point, it would be interesting to calculate the airflow variation of the system $A F R_{-S U P P L Y}$ assuming that: (i) $T_{\text {supply }}$ respects its $S P_{-} S U P P L Y_{-} S C_{-}$initial and (ii) like the previous value, $T_{\text {supply }}$ but raised by $2{ }^{\circ} \mathrm{C}$ to get it closer to monitoring data.

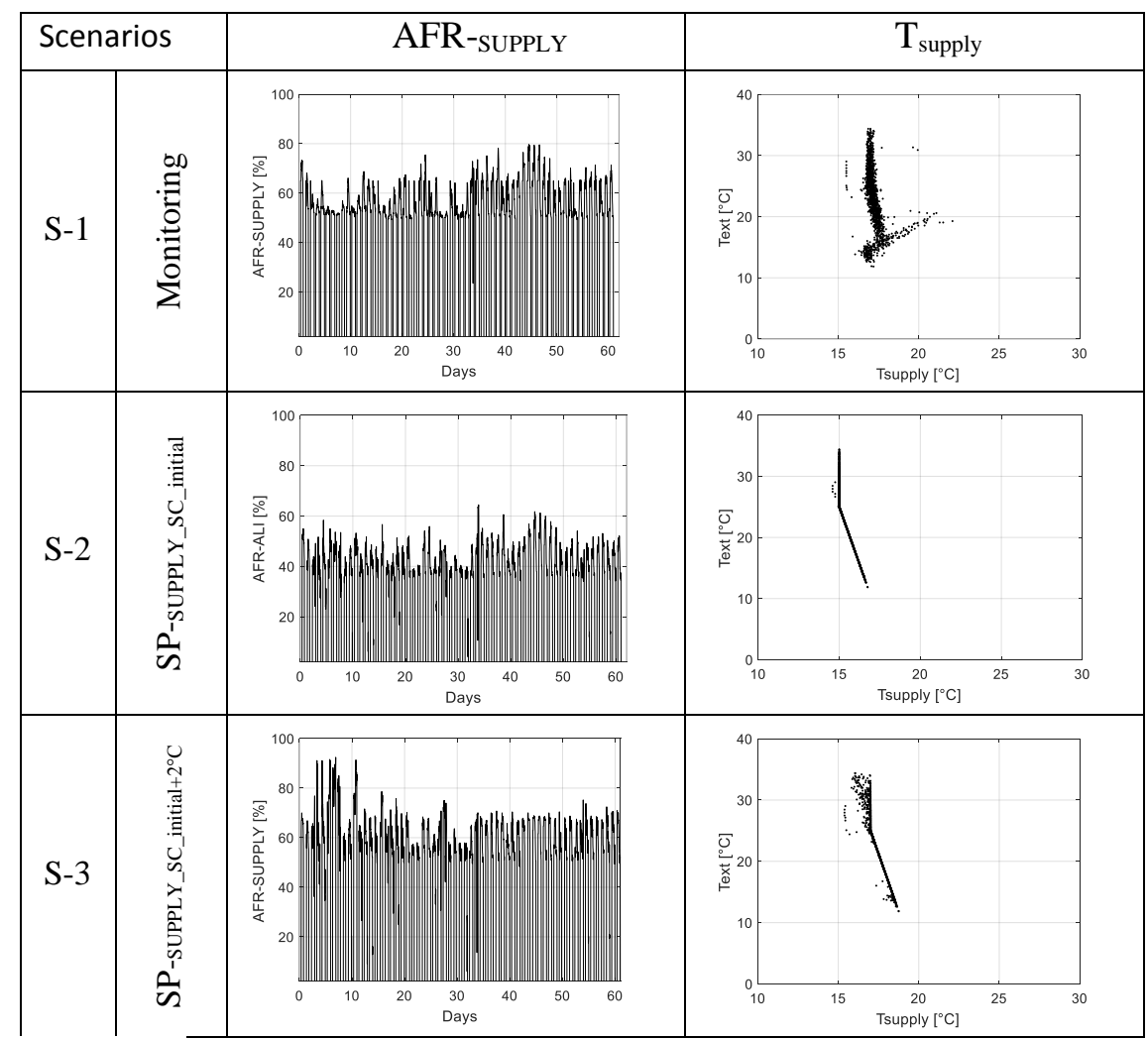

Fig. 7. Variation in AFR-supply, $\mathrm{T}_{\text {supply }} / \mathrm{SP}$ _SuPply and $\mathrm{T}_{\text {ext }}$, (AHU-9 June-July 2013). 
Figure 7 therefore presents the airflow rate variations, as well as the relationships between the outdoor temperature and the air supply temperature, for the following three scenarios:

$S-1$ : Monitoring data with $T_{\text {supply_monitoring }}$ as shown in Figure 6;

$S-2: T_{\text {supply }}=S P_{\text {SUPPLY_SC_initial }}=f\left(T_{\text {ext }}\right)+\operatorname{adjust}\left(A F R_{-S U P P L Y}\right)$;

$S-3: T_{\text {supply }}=S P_{-}$SUPPLY_SC_initial $+2=f\left(T_{\text {ext }}\right)+\operatorname{adjust~}\left(A F R_{-S U P P L Y}\right)+2{ }^{\circ} \mathrm{C}$.

We observe that the new airflow rate (scenario S-2) varies between 40 and $60 \%$ and that $\mathrm{T}_{\text {supply }}$ is around $15^{\circ} \mathrm{C}$ for outside temperatures above $25^{\circ} \mathrm{C}$. We also observe that the airflow rate of scenario S-3 is slightly higher than that obtained from monitoring. The cloud of points showing the $T_{\text {supply }}$ obtained by monitoring (scenario S-1) demonstrates a greater variation of $T_{\text {supply }}$ even if the $T_{\text {supply }}$ values for scenarios S- 1 and S-3 are the same (about $17^{\circ} \mathrm{C}$ ) for outdoor temperatures above $25^{\circ} \mathrm{C}$. Scenario S-2 in Figure 7 confirms a significant oversizing of the AHU-9 system when the $T_{\text {supply }}$ is about $15^{\circ} \mathrm{C}$ for outdoor temperatures above $25^{\circ} \mathrm{C}$. A new oversizing coefficient (OD) that could characterise the degree of overdesign of HVAC systems is proposed in the next section.

\subsection{Overdesign coefficient}

ASHRAE [1] recommends a variation of the fan airflow rate of a VAV system of between 50 and $100 \%$ of its design airflow rate, and fan manufacturers accept this between 40 and $100 \%$. Considering $40 \%$ as the lower limit, we propose the degree of overdesign taking into account the relationship between the fan operating airflow rate and the fan design airflow rate according to the following formula applied for each " $i$ " moment of the monitoring:

$$
O D_{i}=1-\frac{A F R_{-S U P P L Y}}{A F R_{\text {design }}}
$$

The limits of the ODi values will be 0 when $A F R_{-S U P P L Y}$ equals the fan design airflow rate and 0.6 when $A F R_{S}$ SUPPLY is at its lower limit of $40 \%$. So, for a monitoring period having $\mathrm{n}$ measures, we will have:

$$
O D_{\text {monitoring }}=\frac{\sum_{1}^{n} O D_{i}}{\sum_{1}^{n} O D_{i, \max }}
$$

where the denominator value, in our case, is equal to $\mathrm{n} \times 0.6$ ( 0.6 being the maximum value of the ODi). The maximum value for the overdesign coefficient will therefore be $O D_{\text {monitoring }}$ $=1$ for a system that is always running at $40 \%$. The value 0 will be for a system always running at its design airflow rate.

It should be noted that the value of the OD coefficient mentioned above depends on the supply air temperature $\left(T_{\text {supply }}\right)$ control sequences. Therefore, we present in Table 1 the OD coefficients obtained for different scenarios described in the last section. For example, the highest OD value for the AHU-9 system is for scenario S-2, where $T_{\text {supply }}=S P_{-}$SUPPLYSSCinitial $=f\left(T_{\text {ext }}\right)+$ adjustment $\left(A F R_{-S U P P L Y}\right)$. This is quite logical because it is clear from Figure 7 that for this scenario, $\mathrm{T}_{\text {supply }}$ is lowest. Table 1 presents the OD coefficients calculated for the three scenarios studied and for the AHU-1, AHU-9 and AHU-14 systems.

It is seen that the OD values are similar for scenarios S-1 and S-2 for the AHU-9 and AHU-14 systems. These ODs of 0.92 and 0.93 for scenario S-2 are close to 1 , which thus shows that these systems are very oversized. ODs of 0.69 and 0.72 for scenario S- 1 show that the operation of these two systems is improved because the supply air temperature is artificially increased by $2^{\circ} \mathrm{C}$, and therefore, it is higher than that of scenario S-2. The variation of the OD coefficient of the AHU-1 system is lower than that of the AHU-9 and AHU-14 
systems because the $T_{\text {supply_monitoring }}$ of AHU-1 is lower than that that of the other two (Fig. 3A and $3 \mathrm{~B}$ ). However, we note that this system is also oversized, with its OD of 0.85 for scenario S-2.

Table 1. Overdesign coefficient for AHU-1, AHU-9 and AHU-14.

\begin{tabular}{|c|c|c|c|c|}
\hline Scenarios & & AHU-1 & AHU-9 & AHU-14 \\
\hline $\mathrm{S}-1$ & SP SUPPLY (monitoring) & 0.75 & 0.69 & 0.72 \\
\hline S-2 & $\begin{array}{l}\text { SP-sUPPLY_SC_calc. }=\mathrm{f}\left(\mathrm{T}_{\mathrm{ext}}\right)+\text { adjust. }(\mathrm{AFR}- \\
\text { SUPPLY) }\end{array}$ & 0.85 & 0.92 & 0.93 \\
\hline S-3 & $\begin{array}{l}\text { SP-suPPLY_SC_calc. }+2=\mathrm{f}\left(\mathrm{T}_{\text {ext }}\right)+\text { adjust. }(\text { AFR- } \\
\text { sUPPLY })+2^{0} \mathrm{C}\end{array}$ & 0.70 & 0.64 & 0.70 \\
\hline
\end{tabular}

The fact that the AHU-9 and AHU-14 systems serve the zones located on two building facades results in a more balanced system load profile as compared to the AHU-1 system, which serves only one facade. It has already been demonstrated by Stanescu et al. [5] that grouping the building zones served by systems may have an impact on system size, but in the case presented here, the AHU-9 and AHU-14 systems are more oversized than AHU-1, which contrasts with the conclusions of the article mentioned above (Stanescu et al. [4]). In the article, however, it is mentioned that oversizing can result from other elements, including, for example, the design approach used by the system designer. It should be mentioned that the AHU-1 system (installed before the building extension) and the AHU-9 and AHU-14 systems (installed after building extension) were designed by different designers.

\section{Conclusions}

This paper presents the monitoring results for some HVAC systems installed in a university building, which prove that oversizing is a real problem with existing systems. How the zones served by systems are grouped could be a major cause of oversizing but, that can also result from other elements, including, for example, the design approach used by the system designer. The monitoring of systems serving zones located on the same facade (AHU-4 and AHU-1) and systems serving zones on two facades (AHU-9 and AHU-14) confirms this. A proper assessment of the degree of overdesign must take into account the system control sequences and the air supply temperature of the evaluated system. The OD coefficient, determined for the monitored systems, is close to 1 (its maximum value) for the AHU-9 and AHU-14 systems, and is slightly lower for the AHU-1 system. Overdesign must be avoided in designing HVAC systems and an optimisation of HVAC systems design could be the solution needed to reach this objective.

\section{References}

1. ASHRAE Handbook - HVAC Systems and Equipment, SI edition, ASHRAE, Atlanta (2016)

2. S. Kajl, N. Nassif, M. Daigle, Monitoring: un outil d'optimisation de l'opération des systèmes CVCA (1 ere Conférence Internationale sur l'Énergie et l'Architecture Verte, Bangkok, 2003)

3. M. Stanescu, S. Kajl, L. Lamarche, Optimisation du design des centrales frigorifiques des bâtiments (CIFQ, Montréal, 2005)

4. M. Stanescu, S. Kajl, L. Lamarche, HVAC\&R Research 19, 3 (2013) 